\title{
Could A New Measurement, A New Body Shape Index, Replace BMI in Detecting Obesity and Predict The Presence of Obesity and Depression in Asthma Control?
}

\author{
Buket Mermit Çilingir ${ }^{\star}$, Selami Ekin, Hanifi Yildiz, Aysel Sunnetcioglu, Hulya Günbatar \\ Van Yüzüncü Yıl Üniversitesi T⿰р Fakültesi Hastanesi Göğ̈̈s Hastalıkları A.D.
}

Obesity is common in asthma. Depression is thought to be one of the risk factors that increase obesity. It is known that depression has an effect on poor asthma control. Body Mass Index (BMI) is mostly used to define obesity. In recent years, however, the 'A Body Shape Index' (ABSI) based on waist circumference (WC) measurement has been developed and the higher ABSI corresponds to a more central body volume concentration. Our aim was to examine the effect of obesity and depression on asthma control in a way that questions the usability of ABSI, which is new in abdominal obesity measurement.

A total of 99 asthmatic patients aged between 18-80 years who were followed up in Chest Diseases outpatient clinics were included in the study. Demographic and medical history of the patients were recorded. Waist circumference $/ \mathrm{BMI}^{2 / 3} \mathrm{X}$ Length $(\mathrm{m})^{2 / 3}$ was calculated for ABSI measurement. Beck Depression Scale (BDS) and Asthma Control Test (ACT) were applied. Pulmonary Function Test was applied to all patients by the same trained person.

Obese and morbidly obese patients had poor asthma control. We found that the presence of depression caused poor asthma control in all BMI groups. The poorly controlled asthma group and the obese and morbidly obese patients had higher depression scores. BMI and waist circumference were higher in the poorly controlled asthma group ( $p=0.002,0.033$ respectively). However, there was no significant difference between the asthma groups in terms of ABSI ( $\mathrm{p}=0.529)$.

The findings of this study indicate that depressive symptoms, increased BMI and WC were significantly associated with poor asthma control. But ABSI is no superior to BMI in detecting asthma control and depressive mood. However, we should prompt our patients to treatment and exercise, especially for abdominal obesity. We should recommend that asthma patients with depression consult a psychiatrist. In this way, we can control our asthma patients more effectively by minimizing the existing risks.
\end{abstract}

Keywords: Asthma, depression, body mass index, a body shape index

\section{Introduction}

Obesity is the most common cause of preventable death, after smoking $(1,2)$. Increased adipose tissue in obesity is thought to be associated with many diseases such as Type 2 diabetes, metabolic syndrome, hypertension and asthma. Asthma is a lifelong disease that makes it difficult to breathe with narrowing of the airways and continues in attacks. Controlling asthma is important both to prevent the progression of the disease and improve the quality of life (3). Obesity increases asthma attacks and physiological loss of lung function (4). Depression may be one of the risk factor that increase obesity in these patients. $60 \%$ of people with depression are obese and the rate of depression in obese people has doubled $(5,6)$.
Studies have demonstrated the relationship between depression and poor asthma control (7). BMI is the measurement used to assess obesity. However, it is now thought that central or abdominal fat deposition is more dangerous for diseases, whereas BMI does not measure for deposition locations for fat $(8,9)$. WHO reported that Waist circumference (WC) is associated with disease risks and suggests that WC could be used as a alternative to BMI (10). Recently, a new obesity index (A Body Shape Index, ABSI) based on WC was developed. ABSI is a new health indicator reflecting the fatal dangers behind obesity due to both obesity and internal fat and calculated as Waist circumference $/ \mathrm{BMI}^{2 / 3} \mathrm{X}$ Length $(\mathrm{m})^{2 / 3}(11)$.

*Corresponding Author: Buket Mermit Çilingir Van Yüzüncü Yıl Üniversitesi Tıp Fakültesi Göğüs Hastalıkları AD, 65080, Van E-mail: buketmermitcilingir@gmail.com, Tel: (432) 2150474

ORCID ID: Buket Mermit Çilingir: 0000-0002-4946-7029, Selami Ekin: 0000-0001-5922-0348, Hanifi Yıldız: 0000-0003-0735-5034, Aysel Sünnetçioğlu: 0000-0002-3379-3620, Hülya Gübatar: 0000-0002-3504-8915

Received: 24.12.2020, Accepted: 14.07.2021 
In this study, our aim was to examine the effect of obesity and depression on asthma control in a way that questions the usability of ABSI, which is new in abdominal obesity measurement.

\section{Materials and Methods}

A total of 99 asthma patients aged between 18-80 years who were diagnosed and followed up in outpatient clinics of Chest Diseases Department were included in the study.

Height, weight and waist circumference of the patients were measured. Body mass index was calculated by weight / height ${ }^{2}\left(\mathrm{~kg} / \mathrm{m}^{2}\right)$ formula. The range of 27.9-31.1 for men and the range of 27.4-32.2 for women were defined as obese. The range of 31.2-45.4 for men and the range of 32.344.8 for women were defined as morbidly obese. Waist circumference / BMI 2/3 X length (m) ${ }^{2 / 3}$ were calculated for A Body Shape Index measurement. The ABSI is indicated numerically. It does not have a classification as in BMI.

Steroid use, comorbidities and psychiatric fallowup were determined as the hospital system records of patients who were diagnosed by a doctor and received regular treatment for at least one years were obtained.

Pulmonary Function Test was applied to all patients by the same trained person. Asthma Control Test was applied. If total score is 25 , it is evaluated as full control, 24-20 as partial control and $\leq 19$ as non-control (12).

Beck Depression Scale consisting of 21 questions was applied. In this test, the person is asked to choose the most suitable one among four quarters. Each item gets incremental points

between $0-3$ and the total score is obtained by summing them. Total score ranges from $0-9$ point: normal, 10-18 point: mild depression, 19-29 point: moderate depression, 30-63 point: severe depression (13).

The study was approved by the Ethics Committee of Medical Faculty of our hospital (19.12.2019/12) and was conducted in accordance with the principles of the Declaration of Helsinki. Prior to participation, all patients signed written documentation that the informed consent process was completed.

Statistical Analysis: Descriptive statistics for the continuous variables were presented as Mean and Standard deviation while count and percentages for categorical variables. One-way ANOVA was performed for the comparison of group means. Following the ANOVA, Duncan multiple comparison test was used to identify different groups. Chi-square and Fisher's Exact tests were used to determine the relationship between categorical variables. Statistical significance level was considered as 5\% and SPSS (ver: 20) statistical program was used for all statistical computations.

\section{Results}

A total of 99 asthma participants were enrolled in the primary study. When compare according to Asthma Control Test results, demographic characteristics of the individuals are listed in Table 1. In all groups, most participants were female. Asthma control worsened with increasing age. There was no differences between the groups in terms of asthma duration year and smoking. FEV1 and FVC levels were significantly lower in partial control and poor control groups. Steroid use in last 12 months, comorbidities and psychiatric admission rate was higher in poor control group. BMI and waist circumference were higher in poor control group and this was statistically significant $(p=0.002, \quad 0.033$ respectively). But in terms of ABSI, there was no difference in the groups.

The relationship between Beck Depression Scale and BMI classification according to male and female patients are reported in Table 2. Obese and morbid obese asthmatics reported high score in Beck Depression Scale than lean and normal weight asthmatics.

Asthma Control Test (ACT) and BMI classification according to gender are reported in Table 3. As assessed by the Asthma Control Test, obese and morbidly obese patients had poorer asthma control. Poor control asthmatics had higher depression scores as assessed with the Beck Depression Scale (Table 4). Depression symptoms are not shown in full control asthmatics.

When we compare BMI and ABSI in terms of correlation with ACT results, we found that BMI obtained statistically significant results than ABSI (Table 5) ( $\mathrm{p}=0.002, \mathrm{p}=0.529$ respectively). Also when we compare BMI and ABSI in terms of Beck Depression Scale, there was no statistically difference to create significant correlation (Table 6$) \quad(p=0.126$, $\mathrm{p}=0.719$ respectively).

\section{Discussion}

As a result of our study, we found that obese and morbidly obese patients had poor asthma control. We found that the presence of depression caused poor asthma control in all BMI groups. In addition, both 
Table 1. Demographics, functional parameters, and laboratory results of the asthma patients

\begin{tabular}{lcccc}
\hline Parameter & $\begin{array}{c}\text { ACT }<20 \\
\text { Poor control } \\
(\mathrm{n}=59)\end{array}$ & $\begin{array}{c}\text { ACT: } 20-24 \\
\text { Partial control } \\
(\mathrm{n}=34)\end{array}$ & $\begin{array}{c}\text { ACT: 25 } \\
\text { Full control } \\
(\mathrm{n}=6)\end{array}$ & $\begin{array}{c}\mathrm{p} \\
\text { value }\end{array}$ \\
\hline Age (y) & $42.8 \pm 12.9$ & $41.7 \pm 15.4$ & $34 \pm 12.9$ & 0.332 \\
Gender (male /female) & $20 / 40$ & $7 / 27$ & $2 / 4$ & 0.469 \\
Smoking \% (never, current, former) & $46.6 / 41.6 / 10.1$ & $61.8 / 26.5 / 11.8$ & $50 / 50 / 0$ & 0.512 \\
Asthma duration (y) & $5.1 \pm 4.2$ & $5.1 \pm 4.1$ & $2.3 \pm 1.3$ & 0.275 \\
FEV1, lt & $64.8 \pm 12.2 \mathrm{~b} \#$ & $65.2 \pm 14.6 \mathrm{~b}$ & $84.5 \pm 18 \mathrm{a}$ & 0.004 \\
FVC, lt & $64.6 \pm 13.1 \mathrm{~b}$ & $64.6 \pm 15.9 \mathrm{~b}$ & $83.8 \pm 16.3 \mathrm{~b}$ & 0.008 \\
Steroid use in last 12 months (n) & $1.27 \pm 1.59$ & $1.24 \pm 1.61$ & $0.33 \pm 0.51$ & 0.375 \\
Comorbidities (\%) & 56.6 & 50 & 16.6 & 0.373 \\
Psychiatric fallow-up (\%) & 13 & 3 & 1 & 0.266 \\
BMI (kg/m 2) & $30.7 \pm 5.2 \mathrm{a}$ & $26.9 \pm 5.1 \mathrm{~b}$ & $26.3 \pm 2.8 \mathrm{~b}$ & 0.002 \\
Waist circumference (cm) & $100.9 \pm 11.5 \mathrm{a}$ & $94.4 \pm 12.5 \mathrm{~b}$ & $93.8 \pm 13.3 \mathrm{~b}$ & 0.033 \\
ABSI & $0.0803 \pm 0.008$ & $0.0822 \pm 0.0065$ & $0.0805 \pm 0.0053$ & 0.529 \\
\hline Abs
\end{tabular}

Abbreviations: BMI: Body Mass Index, ABSI: A Body Shape Index, ACT: Asthma Control Test, FEV1- forced expiratory volume in 1 second; FVC, forced vital capacity; FEV1/FVC, percentage of forced vital capacity expelled in the first second of forced expiration.

\#: Different lower cases in the same row represent statistically significant differences

Table 2. Beck Depression Scala and BMI Classification According To Gender

\begin{tabular}{|c|c|c|c|c|c|}
\hline & & Beck Depr & ion Scale & & \\
\hline BMI Group & $\begin{array}{c}0-9 \\
\text { Normal } \\
(\mathrm{n}=36) \\
\mathrm{n}(\%)\end{array}$ & $\begin{array}{c}10-18 \\
\text { Mild depression } \\
\qquad \begin{array}{c}(\mathrm{n}=25) \\
\mathrm{n}(\%)\end{array}\end{array}$ & $\begin{array}{c}19-29 \\
\text { Moderate } \\
\text { depression } \\
(\mathrm{n}=18) \\
\mathrm{n}(\%)\end{array}$ & $\begin{array}{c}30-63 \\
\text { Severe } \\
\text { depression } \\
(\mathrm{n}=20) \\
\mathrm{n}(\%)\end{array}$ & $\mathrm{p}$ value \\
\hline $\begin{array}{l}\text { Lean } \\
<20.7 \text { for men } \\
<19.1 \text { for women }\end{array}$ & $0(0)$ & 1(4) & $1(5.6)$ & $0(0)$ & 0.272 \\
\hline $\begin{array}{l}\text { Normal } \\
\text { [20.7-26.4 for men, } \\
19.1-25.8 \text { for women] }\end{array}$ & $8(22.2)$ & $7(28.0)$ & $4(22.2)$ & $3(15.8)$ & \\
\hline $\begin{array}{l}\text { Overweight } \\
\text { [26.5-27.8 for men, } \\
25.9-27.3 \text { for women] }\end{array}$ & $6(16.7)$ & $3(12.0)$ & $0(0)$ & $2(10.5)$ & \\
\hline $\begin{array}{l}\text { Obese } \\
\text { [27.9-31.1 for men, } \\
27.4-32.2 \text { for women] }\end{array}$ & $13(36.1)$ & $9(36.0)$ & $9(50.0)$ & $4(21.1)$ & \\
\hline $\begin{array}{l}\text { Morbid obese } \\
\text { [31.2- } 45.4 \text { for men, } \\
32.3-44.8 \text { for women] }\end{array}$ & $9(25.0)$ & $5(20.0)$ & $4(22.2)$ & 11(52.6) & \\
\hline
\end{tabular}

\section{Abbreviations: BMI: Body Mass Index}

the poorly controlled asthma group and the obese and morbidly obese patients had higher depression scores. BMI and waist circumference were higher in the poorly controlled asthma group. However, there was no significant difference between the asthma groups in terms of ABSI.
Symptoms are more severe in asthma associated with obesity, increased frequency of hospitalization due to attacks and difficult to respond to treatment. In recent studies was reported that obese asthmatics were approximately five times more hospitalized compared to lean 
Table 3. Asthma Control Test (ACT) and BMI Classification According To Gender

\begin{tabular}{|c|c|c|c|c|}
\hline \multicolumn{5}{|c|}{ Asthma Control Test } \\
\hline & $\mathrm{ACT}<20$ & ACT: $20-24$ & ACT:25 & \\
\hline BMI Group & $\begin{array}{c}\text { Poor control } \\
\quad(\mathrm{n}=59)\end{array}$ & $\begin{array}{c}\text { Partial control } \\
\quad(\mathrm{n}=34)\end{array}$ & $\begin{array}{l}\text { Full control } \\
\qquad(\mathrm{n}=6)\end{array}$ & $\mathrm{p}$ value \\
\hline & $\mathrm{n}(\%)$ & $\mathrm{n}(\%)$ & n $(\%)$ & \\
\hline Lean & $1(1.7)$ & $1(3.0)$ & $0(0)$ & 0.014 \\
\hline $\begin{array}{l}<20.7 \text { for men } \\
<19.1 \text { for women }\end{array}$ & & & & \\
\hline $\begin{array}{l}\text { Normal } \\
\text { [20.7-26.4 for men, } \\
19.1-25.8 \text { for women] }\end{array}$ & $6(10.2)$ & $15(42.4)$ & $2(33.3)$ & \\
\hline $\begin{array}{l}\text { Overweight } \\
\text { [26.5-27.8 for men, } \\
25.9-27.3 \text { for women] }\end{array}$ & $6(10.2)$ & $4(12.1)$ & $1(16.7)$ & \\
\hline $\begin{array}{l}\text { Obese } \\
\text { [27.9-31.1 for men, } \\
27.4-32.2 \text { for women] }\end{array}$ & $22(37.3)$ & $10(30.3)$ & $3(50.0)$ & \\
\hline $\begin{array}{l}\text { Morbid obese } \\
\text { [31.2-45.4 for men, } \\
32.3-44.8 \text { for women] }\end{array}$ & $24(40.7)$ & $4(12.1)$ & $0(0)$ & \\
\hline
\end{tabular}

Abbreviations: BMI: Body Mass Index, ACT: Asthma Control Test

Table 4. Data on Asthma Control Test (ACT) and in the distinct Beck Depression Scala

\begin{tabular}{|c|c|c|c|c|c|}
\hline \multicolumn{6}{|c|}{ Beck Depression Scale } \\
\hline & $0-9$ & $10-18$ & $19-29$ & $30-63$ & \\
\hline ACT & $\begin{array}{c}\text { Normal } \\
(\mathrm{n}=36) \\
\mathrm{n}(\%)\end{array}$ & $\begin{array}{l}\text { Mild depression } \\
\qquad \begin{array}{c}(\mathrm{n}=25) \\
\mathrm{n}(\%)\end{array}\end{array}$ & $\begin{array}{l}\text { Moderate depression } \\
\qquad(\mathrm{n}=18) \\
\mathrm{n}(\%)\end{array}$ & 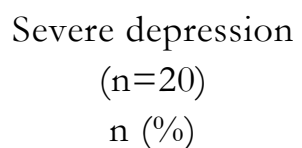 & $\mathrm{p}$ value \\
\hline $\mathrm{ACT}<20$ & & & & & 0.086 \\
\hline $\begin{array}{l}\text { Poor control } \\
(\mathrm{n}=59) \\
\text { ACT: } 20-24\end{array}$ & $19(52.8)$ & $16(64)$ & $12(66.7)$ & $13(63.2)$ & \\
\hline $\begin{array}{l}\text { Partial control } \\
(\mathrm{n}=34) \\
\text { ACT }: 25\end{array}$ & 11(30.6) & $9(36)$ & $6(33.3)$ & $7(36.8)$ & \\
\hline $\begin{array}{l}\text { Full control } \\
(n=6)\end{array}$ & $6(16.7)$ & $0(0)$ & $0(0)$ & $0(0)$ & \\
\hline
\end{tabular}

asthmatics (14). A number of common mechanisms have been identified that increase the incidence of both obesity and asthma. These can be listed as mechanical effects of obesity, inflammation, oxidative stress, genetic and epigenetic factors, lifestyle and environmental exposures.

When we inquired about the applications of the patients to the psychiatric outpatient clinic, we found that those who were under poor asthma control had higher psychiatric admissions. Asthmatic patients with depression may not be able to assess asthma symptoms correctly. Also they may have difficulty in detecting impaired lung functions. Frequent shortness of breath attacks are very stressful for a poorly controlled asthma patient. This may be accompained by different psychological disorders such as depression, panic attacks and anxiety (15). The negative effect of depression on cognitive functioning may affect 
Table 5. Comparison results for BMI and ABSI by Asthma Control Test

\begin{tabular}{llcccc}
\hline & Asthma Control Test & $\mathrm{n}$ & Mean & Std. Dev. & $\mathrm{p}$ \\
\hline \multirow{4}{*}{ BMI } & ACT:25 Full control & 6 & $26.300 \mathrm{~b} \mathrm{\#}$ & 2.8643 & \\
& ACT: $20-24$ Partial control & 34 & $26.991 \mathrm{~b}$ & 5.1151 & 0.002 \\
& ACT<20 Poor control & 59 & $30.742 \mathrm{a}$ & 5.2850 & \\
& Total & 99 & 29.185 & 5.4221 & \\
& ACT:25 Full control & 6 & 0.08050 & 0.005394 & \\
ABSI & ACT: $20-24$ Partial control & 34 & 0.08221 & 0.006556 & 0.529 \\
& ACT<20 Poor control & 59 & 0.08039 & 0.008096 & \\
& Total & 99 & 0.08101 & 0.007458 & \\
\hline
\end{tabular}

Abbreviations: BMI: Body Mass Index, ABSI: A Body Shape Index

\# : Different lower cases represent statistically significant differences

Table 6. Comparison results for BMI and ABSI by Beck Depression Scala

\begin{tabular}{|c|c|c|c|c|c|}
\hline & & & & & $\mathrm{p}$ \\
\hline \multirow[t]{5}{*}{$\mathrm{BMI}$} & 0-9 Normal & 36 & 29.142 & 5.1595 & 0.126 \\
\hline & 10-18 Mild depression & 25 & 27.760 & 4.6242 & \\
\hline & 19-29 Moderate depression & 18 & 28.967 & 5.9298 & \\
\hline & 30-63 Severe depression & 20 & 31.653 & 5.9516 & \\
\hline & Total & 99 & 29.244 & 5.4179 & \\
\hline \multirow[t]{5}{*}{ ABSI } & 0-9 Normal & 36 & 0.08064 & 0.009131 & 0.719 \\
\hline & 10-18 Mild depression & 25 & 0.08224 & 0.006863 & \\
\hline & 19-29 Moderate depression & 18 & 0.08139 & 0.006354 & \\
\hline & 30-63 Severe depression & 20 & 0.07974 & 0.005694 & \\
\hline & Total & 99 & 0.08101 & 0.007458 & \\
\hline
\end{tabular}

Abbreviations: BMI: Body Mass Index, ABSI: A Body Shape Index

decision-making abilities of asthma patents leading low confidence in one's ability to self-manage their asthma (16). Poor health behaviors, such as smoking are more common in patients with depression. These behaviors may aggravate asthma (17). It has shown that proinflammatory cytokines are found at higher levels in patients with depression. These cytokines can cause common somatic symptoms such as fatigue and appetite disorders. (18).

It has been reported that in asthmatics with depressive symptoms, cholinergic-mediated airway narrowing may develop under psychological stress. (19). Medication compliance was reduced in depressive asthmatics (20). In 2002 according the data obtained from the World Health Survey, which collected data from 54 countries by the WHO, 65\% of countries showed a relationship between depression and asthma (21). In a study cocluded after a 20- year follow- up period reported that elevated depressive symptoms were associated with a 1.26- fold increased risk of asthma (independent of BMI) (22).

A large study showed that asthma patients had a 1.6 times greater risk of depression than non- asthma patients (23). Another one showed that asthma control is poorer in less educated, obese, and depressed asthmatics (24). In a meta-analysis, a significant relationship was reported between obesity and depression, especially in women (25). We reached similar resultr in our study.

There is a relationship between concomitant obesity and depression and uncontrolled asthma. This is because depression and obesity can be partially explained as involving a common pathophysiology and common risk factors. The reason for the increase in obesity in asthmatic patients may be a behavior disorder such as tendency to feed with high calorie foods while under physiological stress. Psychological distress causes Hypothalamic-pituitary-adrenal axis dysfunction, increases circulating cortisol levels and results in abdominal obesity (26). Also, psychological distress may be worsen due to the negative body perception of obesity (27).

In our study BMI and waist circumference were higher in poor control asthma group. But there was no statistically significant difference between ABSI and asthma control. There are many studies showing that WC demonstrates the risk of death 
better than BMI $(28,29)$. However, ABSI corresponds to a more central body volume concentration (11).

When we compare BMI and ABSI with correlation analysis in terms of ACT results, we found that BMI gave us statistically significant results than ABSI. When we compared them in terms of Beck Depression Scale, there was no difference that would create a significant correlation. Therefore, we concluded that ABSI did not superior to BMI in determining asthma control and beck depression scale. ABSI shows the risk among those of the same sex and age. These factors may have affected the results.

In recent studies, BMI was calculated according to the height and weight reported by the patients themselves (30). We measured weight, height and waist circumference in our study, so we think our results are more reliable. However, selfassessment questionnaires were used in this study. Thus, the evaluation of the asthma control and depressive scores may be influenced by subjective factors. These 1tems are limitations of our study.

In conclusion, the findings of this study indicate that depressive symptoms, increased BMI and WC were significantly associated with poor asthma control. We should also add that ABSI is no superior to BMI in detecting asthma control and depressive mood. However, we should prompt our patients to treatment and exercise, especially for abdominal obesity. We should recommend that asthma patients with depression consult a psychiatrist. In this way, we can control our asthma patients more effectively by minimizing the existing risks.

\section{References}

1. Prevention and management of the global epidemicof obesity. Report of the WHO Consultation on Obesity 2000. World Health Organization, Geneva, Switzerland.

2. Fock KM, Khoo J. Diet and exercise in management of obesity and overweight. J Gastroenterol Hepatol. 2013 Dec;28 Suppl 4: 5963.

3. Boulet LP. Asthma and obesity Clin Exp Allergy 2013; 43: 8-21.

4. Pakhale S, Doucette S, Vandemheen $\mathrm{K}$, et al. A comparison of obese and nonobese people with asthma: exploring an asthmaobesity interaction. Chest. 2010;137 ( 6 ): 1316 - 1323. Turk Jem 2011; 15: 121-4

5. Gadalla TM. Association of obesity with mood and anxiety disorders in the adult general population. Chronic Dis Can. 2009; 30 ( 1 ): 29- 36 .

6. Hİ Taş, H Ertekin, ÇA Yıldızoğlu, et al. The Relationship Between Eating Behavior and Body Composition with the Severity of Depression in Patients with Major Depressive Disorder Kafkas J Med Sci 2019; 9(1):39-45 doi: 10.5505/kjms.2019.83798.

7. Torres SJ, Nowson CA. Relationship between stress, eating behavior, and obesity. Nutrition. 2007; 23 (11-12): 887 - 894.

8. Kang SM, Yoon JW, Ahn HY, et al. (2011) Android fat depot is more closely associated with metabolic syndrome than abdominal visceral fat in elderly people. PLoS ONE 6: e27694.

9. Lumeng CN, Saltiel AR (2011) Inflammatory links between obesity and metabolic disease. Journal of Clinical Investigation 121: $2111-$ 2117.

10. WHO (2011) Waist Circumference and WaistHip Ratio: Report of a WHO Expert Consultation, Geneva, 8-11 December 2008. Technical report, World Health Organization.

11. Krakauer NY, Krakauer JC. A New Body Shape Index Predicts Mortality Hazard Independently of Body Mass Index Plos One 2012;7:e39504.

12. Ikram A, Kumar V, Taimur M, et al. Role of Montelukast in Improving Quality of Life in Patients with Persistent Asthma. Cureus. 2019 Jun 30;11(6).

13. Monpellier VM, Antoniou EE, Mulkens S,et al. Body image dissatisfaction and depression in postbariatric patients is associated with less weight loss and a desire for body contouring surgery. Surg Obes Relat Dis. 2018 Oct;14(10):1507-1515.

14. Mosen DM, Schatz M, Magid DJ,et al. The relationship between obesity and asthma severity and control in adults. The Journal of allergy and clinical immunology. 2008; 122(3):507- 11.

15. González-Freire B, Vázquez I, Pértega-Díaz S. The Relationship of Psychological Factors and Asthma Control to Health-Related Quality of Life. J Allergy Clin Immunol Pract. 2019 Jul 18:30626-9.

16. Tay TR, Hew M. Comorbid "treatable traits" in difficult asthma: Current evidence and clinical evaluation. Allergy. 2018 Jul;73(7):1369-1382.

17. Ouellet K, Bacon SL, Boudreau M, et al. Individual and combined impact of cigarette smoking, anxiety, and mood disorders on asthma control. Nicotine Tob Res. 2012; 14 ( 8 ): 961 - 969.

18. Van Lieshout RJ, Bienenstock J, MacQueen GM. A review of candidate pathways underlying the association between asthma 
and major depressive disorder. Psychosom Med. 2009 Feb;71(2):187-95.

19. Aboussafy D, Campbell TS, Lavoie K,et al. Airflow and autonomic responses to stress and relaxation in asthma: the impact of stressor type. Int J Psychophysiol. 2005 Sep;57(3):195-201.

20. Cazzola M, Segreti A, Calzetta L, Rogliani P. Comorbidities of asthma: current knowledge and future research needs. Current opinion in pulmonary medicine. 2013; 19(1):36-41. [PubMed: 23114561]

21. Wong KO, Hunter Rowe B, Douwes J, Senthilselvan A. Asthma and wheezing are associated with depression and anxiety in adults: an analysis from 54 countries. Pulmonary medicine. 2013; 2013:929028. [PubMed: 23577252 ]

22. Brunner WM, Schreiner PJ, Sood A, Jacobs DR Jr. Depression and Risk of Incident Asthma in Adults. The CARDIA Study. American journal of respiratory and critical care medicine. 2014; 189(9):1044-51.

23. Walters P, Schofield P, Howard L, Ashworth $\mathrm{M}$, Tylee A. The relationship between asthma and depression in primary care patients: a historical cohort and nested case control study. PLoS One 6: e20750, 2011

24. Demoly P, Paggiaro P, Plaza V, et al. Prevalence of asthma control among adults in France, Germany, Italy, Spain and the UK. European respiratory review: an official journal of the European Respiratory Society. 2009; 18(112):105-12. [PubMed: 20956130 ]

25. D G.Oyekcin, D Yıldız, E M Șahin, S Gür Depression and Anxiety in Obese Patients. Turk Jem 2011; 15: 121-4

26. Dockray S, Susman EJ, Dorn LD. Depression, cortisol reactivity, and obesity in childhood and adolescence. The Journal of adolescent health: official publication of the Society for Adolescent Medicine. 2009; 45(4):344-50. [PubMed: 19766938 ]

27. de Wit L, Luppino F, van Straten A, Penninx B, Zitman F, Cuijpers P. Depression and obesity: a meta-analysis of community-based studies. Psychiatry research. 2010; 178(2):2305. [PubMed: 20462641]

28. Seidell JC (2010) Waist circumference and waist/hip ratio in relation to all-cause mortality, cancer and sleep apnea. European Journal of Clinical Nutrition 64: 35-41.

29. Petursson H, Sigurdsson JA, Bengtsson C, Nilsen TIL, Getz L (2011) Body configuration as a predictor of mortality: comparison of five anthropometric measures in a 12 year followup of the Norwegian HUNT 2 study. PLoS ONE 6: e26621.

30. Santillan AA, Camargo CA. Body mass index and asthma among Mexican adults: the eff ect of using self-reported vs measured weight and height. Int J Obes Relat Metab Disord. 2003; 27 ( 11 ): 1430 - 1433. 